\title{
The North/South Ireland Food Consumption Survey: survey design and methodology
}

\author{
KE Harrington ${ }^{1,2, *}$, PJ Robson ${ }^{3}$, M Kiely ${ }^{4}$, MBE Livingstone ${ }^{3}$, J Lambe ${ }^{5}$ and M Gibney ${ }^{1}$ \\ Irish Universities Nutrition Alliance (IUNA) at: 'Department of Clinical Medicine, Trinity Centre for Health Sciences, \\ St. James's Hospital, Dublin 8, Republic of Ireland: ${ }^{2}$ resent address: IUNA, 2nd Floor, Biotechnology Institute, \\ Trinity College Dublin, Dublin 2, Republic of Ireland: ${ }^{3}$ Northern Ireland Centre for Diet and Health (NICHE), \\ University of Ulster, Coleraine, Co. Londonderry, BT52 1SA, Northern Ireland: ${ }^{4}$ Nutrition Sciences, \\ Department of Food Science and Technology, University College, Cork, Republic of Ireland: \\ ${ }^{5}$ Institute of European Food Studies, Trinity College Dublin, Dublin 2, Republic of Ireland
}

\begin{abstract}
Objective: The purpose of this survey was to establish a database of habitual food and drink consumption in a representative sample of Irish adults aged 18-64 years. Design: A cross-sectional food consumption survey was carried out. Food intake data were collected using a 7-day estimated food diary. Anthropometric data included measurements of weight, height, waist and hip circumferences and body composition using bioelectrical impedance analysis. Questionnaire data included assessments of health, lifestyle and socio-demographic status, levels of physical activity, attitudes to diet and health and restrained eating.

Setting: Northern Ireland and Republic of Ireland between 1997 and 1999.

Results: In total, 1379 adults aged 18-64 years participated in the survey and completed the 7-day food diary. This paper gives details of the methods used to carry out the survey. Sampling, respondent recruitment, dietary assessment, collection of anthropometric and questionnaire data and data management and analysis are described.

Conclusion: The North/South Ireland Food Consumption Survey is unique in being the first food consumption survey ever to be carried out in the Republic of Ireland and Northern Ireland concurrently using the same methodology.
\end{abstract}

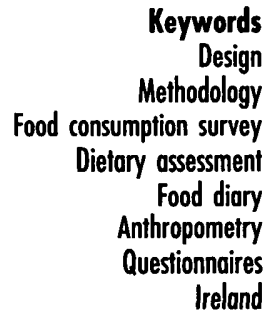

The last major nutrition surveys carried out in the Republic of Ireland and Northern Ireland were the Irish National Nutrition Survey (INNS) ${ }^{1}$ in $1988 / 89$ and the Diet, Lifestyle and Health in Northern Ireland (DLHNI) ${ }^{2}$ survey in 1986/87, respectively. Changing social and demographic circumstances, the growing choice of prepacked convenience foods, the influence of ethnic foods, the greater availability of low- and reduced-fat foods as well as an increasing awareness of 'healthy eating' messages suggest that food consumption patterns in adults are likely to have been substantially modified over the intervening decade since these surveys were undertaken. Thus, new information is required. Data concerning current food consumption in Ireland are also necessary in order to fulfil the requirements of three European Union (EU) Directives which require member states to establish systems to monitor intakes of sweeteners $^{3}$, colours ${ }^{4}$ and food additives (other than colours and sweeteners) ${ }^{5}$. The existing databases, in addition to being over 10 years old, are unsuitable for this purpose as they were designed mainly to assess nutrient intakes.

The primary objective of the North/South Ireland Food Consumption Survey was to establish a database of habitual food and drink consumption in a representative sample of Irish adults aged 18 to 64 years. The survey was carried out by the Irish Universities Nutrition Alliance (IUNA). The IUNA is a formal association of the nutrition units at University College Cork, Trinity College Dublin and the University of Ulster at Coleraine, committed to joint initiatives in education and research. The survey team was based at the nutrition units of the three universities with a co-ordinating nutritionist in each unit. It is anticipated that the data obtained from the present survey will facilitate: (1) the determination of food and nutrient intakes against which current dietary guidelines can be evaluated and future changes monitored; (2) an assessment of adult intakes of food chemicals in order to fulfil EU Directives; and (3) an evaluation of lifestyle 
factors influencing food and nutrient intakes. The present paper describes the design and methods used in collecting data for the North/South Ireland Food Consumption Survey.

\section{Sampling}

Ethical permission was obtained from the Federated Dublin Voluntary Hospitals and St. James's Hospital Joint Research Ethics Committee for the Republic of Ireland, and from the Research Ethical Committee of the University of Ulster for Northern Ireland. Fieldwork was completed over a two-year period between October 1997 and October 1999 with each year divided into two seasons, winter (September-February inclusive) and summer (March-August inclusive). Nationally representative samples were randomly selected for both the Republic of Ireland and Northern Ireland using the 1997 Electoral Register and the 1997-1999 Register of Electors, respectively. A two-stage sampling procedure was employed where district electoral divisions (DEDs) in the Republic of Ireland or electoral wards in Northern Ireland were randomly selected, followed by the random selection of individuals within these areas. Eligible respondents were adults between the ages of 18 and 64 years inclusive who were not pregnant or breast-feeding. A detailed description of the sampling procedure is included elsewhere in the current supplement ${ }^{6}$. A response rate of $63 \%$ was obtained ${ }^{6}$.

\section{Respondent recruitment}

An introductory letter and information about the study were posted to all selected individuals in an area. One week later a survey fieldworker called to explain the survey in more detail, determine eligibility and invite participation. Four visits were made to each respondent's address before they were deemed to be non-contactable. People who declined to participate were asked to provide information concerning age, education, occupation and a reason for non-participation in an attempt to characterise groups of people who declined to participate in the survey. Characteristics of this group have been reported elsewhere ${ }^{6}$. If a potential respondent agreed to participate, they were asked to sign a consent form and the survey commenced.

\section{Survey procedures}

\section{Food intake data collection}

Each respondent kept a written record of all food and drink consumed for 7 days using a 7-day food diary. The choice of the 7-day food diary was governed by the objective of the study, which was to measure food consumption with a view to determining nutrient and food chemical intakes. The same fieldworker made four visits (of on average $30 \mathrm{~min}$ per visit) to the respondent during the recording period: a training session; a visit on day 2; a third visit on day 4 or 5 ; and a final visit on day 8 (at the end of the recording period). Each respondent was visited in his/her home or place of work. During the training session the fieldworker explained how the food diary should be completed. As an example the respondent was instructed to record his/her previous eating occasions, thus reducing the chance of the fieldworker influencing the respondent's reporting of food consumption. Respondents were asked to provide detailed information regarding the types and amounts of all foods, beverages and nutritional supplements consumed over the 7-day period, the time and location of each 'eating occasion', the method of cooking and brand name (where appropriate), leftovers, recipe details and a definition of the 'eating occasion' as the subject perceived it, as either a meal or a snack. Detailed instructions were given on the recording of recipes and food/drink eaten out. It was stressed to respondents that they should not attempt to change or 'improve' their diet during the recording period. During visits on days 2,4 or 5 , and 8 , the fieldworker reviewed the diary recording, checked for completeness, clarified the quantities of food/drink consumed and obtained any further information required. The diary included guidelines on how to record food and drink intake, recording pages, recipe pages and a table for the fieldworker to note usual food used, e.g. milk type. Each eating occasion was filled in on a separate page (with 15-20 pages/diary), the respondent was provided with a new food diary at each visit and the old food diary was collected.

\section{Quantification of food diaries}

As there is a paucity of clear information on the validity and usefulness of different portion size measuring aids, there is little consensus of opinion regarding the most effective tools to use ${ }^{7}$. Although comparative studies are lacking, it is likely that all foods and beverages cannot and should not be quantified in the same way. Therefore the ethos of the survey was to obtain the best estimates possible using a combination of food quantification methods. It is generally accepted that direct weighing is the most precise method of determining amounts of food eaten. However, it is also recognised that for a survey of this size it is not feasible to provide all respondents with dietary scales on the grounds of cost, and to weigh all foods would be unduly invasive and could reduce compliance. On this basis, a hierarchical approach to quantification was developed. Foods and drinks were quantified by eight specific methods according to a quantification protocol. If it was not possible to quantify a food or drink with a method on the first level of the hierarchy, a subsequent method was used. Each fieldworker was responsible for quantification of each food diary they collected. 


\section{(1) Weighing}

Fieldworkers obtained the weights of certain foods in the respondents' homes using portable food scales (Soehnle Vita 8020 food scales $(2000 \mathrm{~g} \times 1 \mathrm{~g})$ and Acculab $(4000 \mathrm{~g} \times 1 \mathrm{~g})$, CMS Weighing Equipment Ltd, London, UK). The foods chosen for this approach were those that were (1) difficult to estimate using other methods and (2) thought to be unlikely to be subject to substantial intra-individual variation. Foods weighed by the fieldworker included breakfast cereals, milk on cereal and milk added to tea and coffee, spreading fats used on bread, slices of bread, and beverages used such as tea, coffee, juices and alcohol.

\section{(2) Photographic food atlas}

The second approach was to ask respondents to describe food quantities that they had eaten in terms of fractions or multiples of the amounts of food shown in the appropriate photograph in an album of food photographs specifically designed for this survey ${ }^{8}$. Photographs are an attractive quantification aid as they are portable, capable of portraying a wide range of foods and relatively easy to

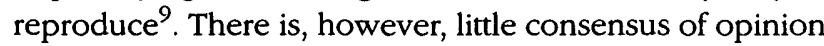
concerning the nature of food photographs suitable for use as quantification aids in dietary surveys. The foods selected for inclusion in the album for use in the survey were foods consumed commonly in Ireland. Those foods that could easily be described in terms of natural units, such as biscuits, eggs and commercially sliced bread, were not included as various studies have suggested that these can be adequately described without the use of portion size aids ${ }^{10-13}$.

Two types of food photograph were produced: reference photographs (RPs) and single food photographs (SFPs). The RPs showed several different types of a particular food in one picture and were intended mainly for identification purposes. Because of the wide range of breads eaten in Ireland, a major difficulty concerns identification of, and nomenclature used for, different types of bread other than standard sliced loaves. Thus 14 reference photographs were taken solely of different types of bread from different regions throughout Ireland. The SFPs showed only one portion of one type of food. The majority of the food weights shown in these photographs were derived from UK average portion weight data ${ }^{14}$. The resulting album contained 61 colour prints $(18.0 \mathrm{~cm} \times 12.5 \mathrm{~cm})$.

\section{(3) Manufacturers' information}

For some foods, it was possible to obtain the amounts eaten by deriving them from weights printed on food packaging. These included confectionery, savoury snacks, chilled and frozen foods, franchised fast foods, canned or bottled goods and packaged bakery goods. To facilitate collection of such data, fieldworkers asked respondents to collect all packaging of food and beverages consumed in a storage box/bag provided. Manufacturers' information was then added to an Extended Menu Search $\left(\mathrm{EMS}^{\oplus}\right)$ facility on the nutritional analysis program (WISP $^{\odot}$, Tinuviel Software, Warrington, $\mathrm{UK}$ ), which interfaced with the food diary data entry system (WISP-DES ${ }^{\mathcal{}}$, Tinuviel Software, Warrington, UK) enabling fieldworkers to quickly code and quantify food and drink consumed.

\section{(4) IUNA information}

Average portions were ascertained for certain foods by the survey team. These foods included fruits, vegetables, processed meats, meat products, cakes, breads, bread rolls and take-away foods.

\section{(5) Data collected as part of previous UK studies}

These included weights on cereals, meat dishes, egg and egg dishes, desserts/puddings, vegetables, sauces and others ${ }^{15}$.

(6) Food Portion Sizes ${ }^{14}$ was consulted if none of the previous methods provided quantities for foods or drinks.

\section{(7) Housebold measures}

Household measures were also used to quantify foods eaten.

\section{(8) Estimated}

Food quantities were defined as 'estimated' if the fieldworker made an assessment of the amount likely to have been consumed, based on their knowledge of the respondent's general eating habits observed during the recording period.

In order to quantify cooked foods and recipes for which raw weights were available, the cooked food weights were derived from the raw weights and adjusted for weight gain or loss on cooking according to published guidelines $^{16-18}$.

\section{Coding, data entry and analysis of food diaries}

Food diaries were coded and data were entered by fieldworkers using a customised computer program called the Weighed Intake Software Package - Data Entry System $\left(\right.$ WISP-DES ${ }^{\odot}$ ) version $1.25 \mathrm{C}$ (Tinuviel Software, Warrington, UK), installed on laptop computers. Completed food diaries were then exported from fieldworkers' laptops and imported into a customised nutritional analysis program called the Weighed Intake Software Package (WISP ${ }^{\mathbb{C}}$ ) (Tinuviel Software, Warrington, UK). The food diaries were analysed for nutrient data and all food and nutrient data were imported into the Statistical Package for Social Sciences $\left(\right.$ SPSS $^{\Theta}$ ) for Windows version 8.0 (SPSS Inc., Chicago, IL). 


\section{Quality control of food diary data}

Health science professionals, nutritionists and dieticians were employed as fieldworkers and each was responsible for the collection, quantification, coding and data entry of their own food diaries. Nutritionists reviewed diaries in each centre. One in every eight diaries was checked on a line-by-line basis by a trained nutritionist in the Republic of Ireland. This entailed a review of every entry from a food diary for accuracy of quantification, food code used and data entry. In the North, the co-ordinating nutritionist checked every diary in this way.

The quantification protocol described above ensured quality control for data entry of food portions. WISP$\mathrm{DES}^{\mathcal{O}}$ also incorporated over-range checks for portion sizes by generating a warning if a portion size was entered as five times a large portion size. During the coding and data entry of foods into WISP-DES ${ }^{\mathbb{C}}$, an Extended Menu Search $\left(\mathrm{EMS}^{\mathcal{\odot}}\right)$ function developed specifically for the present survey was used (Tinuviel Software, Warrington, UK). EMS ${ }^{\circledR}$ is a database that uses the food group framework of McCance $\mathcal{E}$ Widdowson's The Composition of Foods ${ }^{16-25}$, where a food code is linked to specific data on foods that were represented by that food code. These data include manufacturer-specific food portion sizes and product descriptions.

Fieldworkers completed training workshops to: (1) learn interviewing techniques, respondent recruitment and dietary assessment training of respondents - roleplaying was undertaken with nutritionists (who had expertise in diet survey methodology) using closed-circuit televisions; (2) assess each fieldworker's competency in the quantification and coding of food diaries - this included familiarisation of the fieldworker with the range of products currently available on supermarket shelves and the collection of average portion size data; and (3) train fieldworkers in the collection of anthropometric measurements using standardised procedures.

\section{Food composition database}

The food composition database used by WISP-DES ${ }^{\circledR}$ and WISP $^{\odot}$ contains data from the 5 th edition of McCance $\mathcal{E}$ Widdowson's The Composition of Foods ${ }^{16}$ and all nine supplements ${ }^{17-25}$. This food composition database was expanded to include generic Irish products and new products on the market, to allocate brand codes to specific products, to enable analysis of recipes and to include nutritional supplements. Fieldworkers' queries on coding and the generation of new food codes were managed by a co-ordinating nutritionist. The decision to create a new food code was based on the following criteria: (1) the food was not present or was different from other foods in the existing nutrient database; (2) the food was a diet product with little nutrient content but contained sugar substitutes (artificial sweeteners); or (3) the food was present in the database but the nutrient content was very different to existing codes. The creation of a new food code also depended on the number of respondents the food was consumed by and the frequency of consumption. Foods were assigned a new food code under the food group categories defined by the McCance and Widdowson database ${ }^{16-25}$. The nutrient composition of new food codes was obtained from manufacturer's nutritional information and analysis of recipes. One thousand and ten new food codes (including 148 nutritional supplements) were created and added to the food composition database.

\section{Antbropometric measurements}

Five measurements were taken in this survey: weight, height, waist and hip circumferences and body composition using bioelectrical impedance analysis. The procedures used in taking the anthropometric measurements are described in detail elsewhere ${ }^{26}$. All measurements except height and body composition were performed in duplicate. Body mass index (BMI) was derived from weight and height measurements. Prior to and on completion of the survey, the Seca Alpha 770 digital personal weighing scales $(200 \mathrm{~kg} \times 0.1 \mathrm{~kg}$ ) (CMS Weighing Equipment Ltd, London, UK) used in the Republic of Ireland were verified for accuracy of weighing up to $180 \mathrm{~kg}$ by the Legal Metrology Service, Dublin and up to $100 \mathrm{~kg}$ by technicians of the Northern Ireland Centre for Diet and Health (NICHE). No need for adjustment was found. The bioelectrical impedance analyser (Bodystat 1500, Bodystat Ltd, Douglas, Isle of Man, UK) used to measure body composition automatically performs its own calibration check each time a measurement is taken. Periodically, fieldworkers also checked the calibration separately according to the manufacturer's instructions.

\section{Questionnaire design}

Respondents were asked to complete six questionnaires: a Health, Lifestyle and Socio-demographic Questionnaire, a Physical Activity Questionnaire, a Dutch Eating Behaviour Questionnaire (DEBQ) $)^{27,28}$, an Attitudinal Questionnaire, a Meat Questionnaire and an Evaluation Questionnaire. All questionnaires were self-administered.

The Health, Lifestyle and Socio-demographic Questionnaire was used to allow an assessment of the influences of social and lifestyle factors on food choice and/or nutrient intake. The first section of the questionnaire was designed to provide background information on sex, age, smoking habits, usual alcohol consumption, medical conditions, weight changes in the past five years and changes in dietary habits in the past year. The second section was used to describe the socio-economic status of each respondent.

The Pbysical Activity Questionnaire measured habitual physical activity. This questionnaire was developed by and provided by kind permission of the Institute of Public Health, University of Cambridge, UK. The questionnaire was divided into three sections: (1) physical activity 
patterns in and around the home, (2) work-related activity patterns and travel and (3) recreational activity. The data were analysed by the Institute of Public Health, Cambridge to produce variables that expressed the energy cost of all self-reported activity in household, work and recreational activities as an activity metabolic equivalent (MET) index by assigning a multiple of resting metabolic rate (MET score) to each activity ${ }^{29}$.

Recent studies have indicated that the prevalence of underreporting of food intake is high, particularly among obese adults ${ }^{30}$. Thus it has been recommended that a means of identifying weight-conscious individuals should be included in food surveys, as these individuals in particular may be prone to misrepresentation of food intakes $^{30}$. The Dutch Eating Behaviour Questionnaire ${ }^{27,28}$ was used in the present survey for this purpose. This is a short, multiple-choice, self-administered questionnaire that measures three eating behaviour scales: restraint, emotional and external eating.

Respondents were also asked to complete an Attitudinal Questionnaire designed to assess attitudes to diet and health and a Meat Questionnaire that assessed respondents' understanding of 'red meat', meat food choices and cooking practices. An Evaluation Questionnaire was used to assess reasons for participation and how respondents felt about participation.

\section{Questionnaire data management}

All questionnaire data were entered into a customised Questionnaire - Data Entry Program $\left(\right.$ QDES $^{\mathcal{C}}$ ) $($ Tinuviel Software, Warrington, UK). This program validated the data entry by requiring dual-data entry and rules-based validation processes where only certain answers were permitted. Validated questionnaires were then imported into the customised questionnaire data collection system called the Questionnaire Consolidator program (QCON ${ }^{\circledR}$ ) version 1.1D (Tinuviel Software, Warrington, UK). This allowed collected data to be consolidated into an output file before importing into SPSS $\left.{ }^{(}\right)$for Windows version 8.0 (SPSS Inc., Chicago, IL) to produce a database for statistical analysis. Further quality control was carried out on all questionnaires at the SPSS ${ }^{\circledR}$ stage.

All food, nutrient and questionnaire data were imported into SPSS $^{\circledR}$ for Windows version 8.0 (SPSS Inc., Chicago, IL). These were compiled into a fully integrated relational database, which means that each respondent's ID number links every piece of information that is collected from that respondent.

\section{Conclusion}

The North/South Ireland Food Consumption Survey is unique in being the first survey ever to be carried out in the Republic of Ireland and Northern Ireland concurrently using the same methodology. It provides an up-to-date database of habitual food and drink consumption in conjunction with data on socio-demographic status, physical activity levels, anthropometry, attitudes and restrained eating patterns in a representative sample of Irish adults.

\section{References}

1 Lee P, Cunningham K. The Irish National Nutrition Survey. Dublin: Irish Nutrition and Dietetic Institute, 1990.

2 Barker ME, McClean SI, McKenna PG, et al. Diet, Lifestyle and Health in Northern Ireland. Coleraine: University of Ulster, 1988.

3 European Parliament and Council Directive 94/35/EC on sweeteners for use in foodstuffs, 1994.

4 European Parliament and Council Directive 94/36/EC on colours for use in foodstuffs, 1994.

5 European Parliament and Council Directive 95/2/EC on food additives other than colours and sweeteners for use in foodstuffs, 1995.

6 Kiely M, Flynn A, Harrington KE, Robson PJ, Cran G. Sampling description and procedures used to conduct the North/South Ireland Food Consumption Survey. Public Health Nutr. 2001; 4(5A): 1029-35.

7 Cypel YS, Guenther PM, Petot GJ. Validity of portion-size measurement aids: a review. J. Am. Diet. Assoc. 1997; 97(3): 289-92.

8 Robson PJ. Photographic food atlas for the North/South Ireland Food Consumption Survey, 1997.

9 Lucas F, Niravong M, Villeminot S, Kaaks R, ClavelChapelon F. Estimation of food portion sizes using photographs: validity, strengths, weaknesses and recommendations. J. Hum. Nutr. Diet. 1995; 8: 65-74.

10 Young CM, Chalmers FW, Church HN, Clayton MM, Hagan GC, Steele BF, Tucker RE, Foster WD. Subject's ability to estimate food portions. Mass. Agric. Exp. Stn. Bull. 1952; 1(469): 63-77.

11 Guthrie HA. Selection and quantification of typical food portions by young adults. J. Am. Diet. Assoc. 1984; 84: 1440-4.

12 Haraldsdottir J, Holm L, Fromog Lone V, Nielsen S. Estimering af portionsstorrelser ved hjaelp af modeller [Estimation of portion sizes with the help of models]. Naringsforskning 1985; (29): 59-65.

13 Wein EE, Sabry JH, Evers FT. Recalled estimates of food portion size. J. Am. Diet. Assoc. 1989; 89(7): 962-4.

14 Ministry of Agriculture, Fisheries and Food (MAFF). Food Portion Sizes. London: The Stationery Office, 1997.

15 Livingstone MBE. Portion sizes of food and drink collected as part of UK studies. Unpublished data. Coleraine: Northern Ireland Centre for Diet and Health (NICHE), University of Ulster, 1997.

16 Holland B, Welch AA, Unwin ID, Buss DH, Paul AA, Southgate DAT. McCance \& Widdowson's The Composition of Foods, 5th ed. Royal Society of Chemistry and Ministry of Agriculture, Fisheries and Food. London: HMSO, 1995.

17 Chan W, Brown J, Lee SM, et al. Meat, Poultry and Game. Fifth Supplement to McCance $\mathrm{E}$ Widdowson's The Composition of Foods, 5th ed. Royal Society of Chemistry and Ministry of Agriculture, Fisheries and Food. London: HMSO, 1995.

18 Chan W, Brown J, Church SM, et al. Meat Products and Dishes. Sixth Supplement to McCance \& Widdowson's The Composition of Foods, 5th ed. Royal Society of Chemistry and Ministry of Agriculture, Fisheries and Food. London: HMSO, 1996

19 Holland B, Unwin ID, Buss DH. Cereal and Cereal Products. Third Supplement to McCance \& Widdowson's The Composition of Foods, 4th ed. Royal Society of 
Chemistry and Ministry of Agriculture, Fisheries and Food. London: HMSO, 1998.

20 Holland B, Unwin ID, Buss DH. Milk Products and Eggs. Fourth Supplement to McCance \& Widdowson's The Composition of Foods, 4th ed. Royal Society of Chemistry and Ministry of Agriculture, Fisheries and Food. London: HMSO, 1989.

21 Holland B, Unwin ID, Buss DH. Vegetables, Herbs and Spices. Fifth Supplement to McCance \& Widdowson's The Composition of Foods, 4th ed. Royal Society of Chemistry and Ministry of Agriculture, Fisheries and Food. London: HMSO, 1991.

22 Holland B, Unwin ID, Buss DH. Fruit and Nuts. First Supplement to McCance $E$ Widdowson's The Composition of Foods, 5th ed. Royal Society of Chemistry and Ministry of Agriculture, Fisheries and Food. London: HMSO, 1992.

23 Holland B, Welch AA, Buss DH. Vegetable Dishes. Second Supplement to McCance $\&$ Widdowson's The Composition of Foods, 5th ed. Royal Society of Chemistry and Ministry of Agriculture, Fisheries and Food. London: HMSO, 1992.

24 Holland B, Brown J, Buss DH. Fish and Fish Products. Third Supplement to McCance \& Widdowson's The Composition of Foods, 5th ed. Royal Society of Chemistry and Ministry of Agriculture, Fisheries and Food. London: HMSO, 1993.
25 Chan W, Brown J, Buss DH. Miscellaneous Foods. Fourth Supplement to McCance \& Widdowson's The Composition of Foods, 5th ed. Royal Society of Chemistry and Ministry of Agriculture, Fisheries and Food. London: HMSO, 1994.

26 McCarthy SN, Harrington KE, Kiely M, Flynn A, Robson PJ, Livingstone MBE, Gibney MJ. Analyses of the anthropometric data from the North/South Ireland Food Consumption Survey. Public Health Nutr. 2001; 4(5A): 1099-106.

27 van Strien $T$. The concurrent validity of a classification of dieters with low versus high susceptibility toward failure of restraint. Addict. Bebav. 1997; 22: 587-97.

28 van Strien T, Frijters JER, Bergers GPA, Defares PB. The Dutch Eating Behaviour Questionnaire (DEBQ) for assessment of restrained, emotional and external eating behaviour. Int. J. Eat. Disord. 1986; 5: 295-315.

29 Livingstone MBE, Robson PJ, McCarthy S, Kiely M, Harrington K, Browne P, Galvin M, Wareham NJ, Rennie KL. Physical activity patterns in a nationally representative sample of adults in Ireland. Public Health Nutr. 2001; 4(5A): 1107-16.

30 Black AE, Prentice AM, Goldberg GR, Jebb SA, Bingham $\mathrm{SA}$, Livingstone $\mathrm{MBE}$. Measurements of total energy expenditure provide insights into the validity of dietary measurements of energy intake. J. Am. Diet. Assoc. 1993; 90: $572-9$. 